\title{
Plasma membrane proteomic analysis of human Gastric Cancer tissues: revealing flotillin 1 as a marker for Gastric Cancer
}

Wen Gao ${ }^{1,4 \dagger}$, Jing Xu ${ }^{1,4 \dagger}$, Fuqiang Wang ${ }^{3}$, Long Zhang ${ }^{1}$, Rui Peng ${ }^{1}$, Yongqian Shu ${ }^{4}$, Jindao Wu ${ }^{1 *}$, Qiyun Tang ${ }^{2^{*}}$ and Yunxia Zhu ${ }^{3^{*}}$

\begin{abstract}
Background: Gastric cancer remains the second leading cause of cancer-related deaths in the world. Successful early gastric cancer detection is hampered by lack of highly sensitive and specific biomarkers. Plasma membrane proteins participate and/or have a central role in the metastatic process of cancer cells and are potentially useful for cancer therapy due to easy accessibility of the targets.

Methods: In the present research, TMT method followed by mass spectrometry analysis was used to compare the relative expression levels of plasma membrane proteins between noncancer and gastric cancer tissues.

Results: Of a total data set that included 501 identified proteins, about 35\% of the identified proteins were found to be plasma membrane and associated proteins. Among them, 82 proteins were at least 1.5-fold up- or down-regulated in gastric cancer compared with the adherent normal tissues.

Conclusions: A number of markers (e.g. annexin A6, caveolin 1, epidermal growth factor receptor, integrin beta 4) were previously reported as biomarkers of GC. Additionally, several potential biomarkers participated in endocytosis pathway and integrin signaling pathways were firstly identified as differentially expressed proteins in GC samples. Our findings also supported the notion that flotillin 1 is a potential biomarker that could be exploited for molecular imaging-based detection of gastric cancer. Together, the results show that subcellular proteomics of tumor tissue is a feasible and promising avenue for exploring oncogenesis.
\end{abstract}

Keywords: TMT, Gastric cancer, Plasma membrane, Flotillin 1, Biomarker

\section{Background}

Gastric cancer(GC) is the second leading cause of cancer related deaths which kill about 800000 people annually [1]. It is a highly aggressive malignant disease with the overall 5 year survival rate (5YSR) of 24\% [2]. The major reason for this poor outcome is the difficulty in the detection of early stage GC when

\footnotetext{
*Correspondence: wujindao@njmu.edu.cn; tqy831@163.com; zhuyx@njmu. edu.cn

${ }^{\dagger}$ Equal contributors

'Key Laboratory of Living Donor Liver Transplantation, Ministry of Public Health, Department of Liver Transplantation Center, The First Affiliated Hospital of Nanjing Medical University, 300 GuangZhou Road, Nanjing 210029, China

2Department of Gastroenterology, The first affiliated hospital of Nanjing medical university, 300 GuangZhou Road, Nanjing 210029, China

${ }^{3}$ Analysis Center of Nanjing Medical University, 104 Hanzhong Road, 210009

Nanjing, China

Full list of author information is available at the end of the article
}

treatment could improve long term survival of patients. Therefore, the identification of tumor biomarkers for early detection plays an important role in improving diagnosis and treatment of GC. Unfortunately, tumor biomarkers such as CEA and CA19-9 that are currently utilized for the detection of GC in clinical practice are not specific and sensitive enough; with their sensitivity in the range of $18 \%-57 \%$ [3]. Consequently, discovery of the valuable biomarkers of $\mathrm{GC}$ remains a worthy task.

Plasma membrane encloses the cell and maintains the essential boundaries between the cytosol and the extracellular environment. The proteins constitute approximately $50 \%$ (by mass) of the cell surface membrane [4]. Proteins located in plasma membrane mediate most functions of the membrane, such as acting as sensors for 
external signals, transporters of specific molecules and the connection point of the membrane to the cytoskeleton, the extracellular matrix and adjacent cells $[5,6]$. Significantly, these proteins constitute more than $45 \%$ of current drug targets, with $25-30 \%$ of drugs targeting Gprotein coupled receptors $[7,8]$. Defining the plasma membrane proteome is of great interest due to the fundamental role of membrane proteins [9]. Moreover, profiling plasma membrane markers in specific disease stage has great potential for identifying novel biomarkers and subsequent therapeutic targets [8]. Her2 [10], cMet, and EGFR [11] are classical examples of plasma membrane proteins against which small molecules and biologics have been successfully developed and implemented in the clinic [10-12]. Attempts have succeeded in identifying potential plasma membrane biomarkers of GC from cell lines. These include but are not limited to SLC3A2. However, global proteomic analysis of membrane-enriched samples from normal versus GC tissues has not been reported before.

Stable isotope-based quantitative proteomics approach for identification and quantification of proteins has provided new possibilities in the field of biomarker discovery [13]. The isotopes can be incorporated metabolically as in SILAC or chemically as in isobaric labeling methods include isobaric tag for relative and absolute quantification (iTRAQ) and tandem mass tag (TMT) [14,15]. The 2-plex and 6-plex tandem mass tags (TMTs), through the incorporation of, respectively, one $\left({ }^{13} \mathrm{C}\right)$ and five $\left({ }^{13} \mathrm{C}\right.$ or $\left.{ }^{15} \mathrm{~N}\right)$ stable isotopes, perform relative protein quantification between two and up to six samples [16]. This method is successfully used to screen for biomarkers in periodontal disease, colorectal cancer [15], breast cancerand so on $[17,18]$.

In this study, we used TMT label combined with LCMS/MS to compare the expression level of plasma membrane proteins between a pair of "normal" and gastric cancer tissues, thereby allowing identification of plasma membrane-associated biomarkers. Our data revealed flotillin 1 plasma membrane protein to be a potential biomarker for GC detection.

\section{Methods}

\section{Patient samples}

GC samples with stage I tumors((AJCC 6th Edition Stage I disease, with minimal depth of invasion into mucosa and no metastatic lymph nodes) and matched normal tissue samples (50-200 mg) were obtained from surgical resection specimens at the department of pathology, snap frozen in liquid nitrogen, and stored at $-80^{\circ} \mathrm{C}$ until use and subjected to routine pathological examination at Jiangsu province hospital. The patients' age ranged from 32 to 90 years, only 12 patients were GC and were available for further studies. Written informed consent was obtained from each patient before surgery. This study was approved by the Ethics Committee of Nanjing Medical University with an Institutional Review Board (IRB) number of 2012NFLZ-32. The tumor and control samples were pooled separately and subjected to proteomic analysis.

\section{Plasma membrane purification and protein lysis}

Plasma membrane was enriched as previously described [19]. Briefly, tissues were lysed by hypotonic buffer (10 mM Trisbase, $1.5 \mathrm{mM} \mathrm{MgCl}_{2}, 10 \mathrm{mM} \mathrm{NaCl}, \mathrm{pH}$ 6.8) for $5 \mathrm{~min}$ followed by centrifugation at $300 \times g$ for $5 \mathrm{~min}$, then resuspended in gradient buffer $(0.25 \mathrm{M} \mathrm{Su}$ crose, $10 \mathrm{mM}$ HEPES, $100 \mathrm{mM}$ Succinic acid, $1 \mathrm{mM}$ EDTA, $2 \mathrm{mM} \mathrm{CaCl}_{2}, 2 \mathrm{mM} \mathrm{MgCl} 2, \mathrm{pH} 7.4$ ) and homogenized. The homogenate was centrifuged at $1,000 \times g$ for $10 \mathrm{~min}$ and the supernatant was collected. Subsequently, the supernatant was centrifuged at $100000 \times g$ for $30 \mathrm{~min}$. The pellet was purified membranes which were resuspended in $2 \mathrm{~mL}$ gradient buffer by homogenization and mixed with $1.9 \mathrm{~mL}$ Percoll (Amersham Biosciences, Uppsala,Sweden) containing 10\% PBS and $0.19 \mathrm{~mL}$ $2.5 \mathrm{M}$ sucrose in an Easy-Seal tube (polyallomer, $5 \mathrm{~mL}$, Sorvall). The tube was filled with gradient buffer, capped and centrifuged at $120000 \times g$ for $15 \mathrm{~min}$. The pellet was washed with ice-cold PBS three times and suspended in $150 \mu \mathrm{l}$ of SDS lysis buffer and stored at $-80^{\circ} \mathrm{C}$. The protein concentrations were determined by the Bradford method.

\section{Protein digestion and peptide tandem mass tag(TMT) labeling}

Protein digestion and TMT labeling were done as previously described [20]. $1 \mathrm{mg}$ of plasma membrane protein from normal or GC samples was reduced with $10 \mathrm{mM}$ DTT at $60^{\circ} \mathrm{C}$ for $1 \mathrm{~h}$, alkylated with $55 \mathrm{mM}$ IAA for 45 min at room temperature in the dark and digestion with trypsin overnight at $37^{\circ} \mathrm{C}$. Tryptic peptides were desalted and then dried in vacuo (Speed Vac, Eppendorf). $20 \mu \mathrm{g}$ of proteins was labeled for $1 \mathrm{~h}$ at room temperature by adding $5 \mu \mathrm{L}$ of the TMT reagent. The peptides were labeled with isobaric tags and mixed at 1:1 ratio based on total peptide amount. The TMT labeled proteins were stored at $-80^{\circ} \mathrm{C}$ until used.

\section{SCX fractionation separation}

SCX fractionation separation was done as previously described [20]. Peptide mixtures were resuspended in $10 \mathrm{mM} \mathrm{NH}{ }_{4} \mathrm{COOH}, 5 \% \mathrm{ACN}(\mathrm{pH} 2.7)$, and subjected to cation ion exchange columns $(1 \mathrm{~mm}$ ID $\times 10 \mathrm{~cm}$ packed with Poros $10 \mathrm{~S}$, DIONEX, Sunnyvale,CA, USA) with the UltiMate 3000 HPLC system. The separation was performed by applying a two-buffer system. Buffers A and $\mathrm{B}$ were prepared as follows: buffer A, $5 \mathrm{mM}$ ammonium formate, $5 \% \mathrm{ACN}(\mathrm{pH}=2.7)$; buffer $\mathrm{B}, 800 \mathrm{mM}$ 
ammonium formate, $5 \% \mathrm{ACN}(\mathrm{pH}=2.7)$. The following gradient was employed: $0 \%$ to $30 \% \mathrm{~B}$ for $21 \mathrm{~min}, 30 \%$ to $56 \%$ B for $7 \mathrm{~min}, 56 \%$ B to $100 \%$ B for $1 \mathrm{~min}, 100 \%$ B for $3 \mathrm{~min}, 100 \% \mathrm{~B}$ to $0 \%$ for $1 \mathrm{~min}$ and $0 \%$ for $20 \mathrm{~min}$ before the next run. Twenty fractions in total were collected and lyophilized.

\section{Mass spectrometry analysis}

Mass spectrometry analysis was done as previously described [21]. The labeled peptides were analyzed on the LTQ Orbitrap-Velos instrument (Thermo Fisher, USA) connecting to a Nano ACQUITY UPLC system via a nanospray source. The reverse-phase separation of peptides was performed using the buffer $\mathrm{A}(2 \% \mathrm{ACN}, 0.5 \%$ acetic acid) and buffer B ( $80 \% \mathrm{ACN}, 0.5 \%$ acetic acid); the gradient was set as following: $4 \%$ to $9 \%$ buffer B for 3 min, $9 \%$ to $33 \%$ buffer B for $170 \mathrm{~min}, 33 \%$ to $50 \%$ buffer B for $10 \mathrm{~min}, 50 \%$ to $100 \%$ buffer B for $1 \mathrm{~min}, 100 \%$ buffer B for $8 \mathrm{~min}, 100 \%$ to $4 \%$ buffer B for $1 \mathrm{~min}$. For analysis of plasma membrane proteins, one full scan was followed by the selection of the eight most intense ions for collisioninduced dissociation (CID) fragmentation (collision energy $35 \%)$. The most intense product ion from the MS2 step was selected for higher energy collision-induced dissociation (HCD)-MS3 fragmentation.

\section{Protein identification and quantification}

Protein identification and quantification were done as previously described [21]. Maxquant (version 1.2.2.5) was used to identify the raw spectra acquired from precursor ions as described [22]. Search parameters were set as following: precursor mass tolerance of \pm 20 parts per million (ppm); 0.5-dalton product ion mass tolerance; trypsin digestion; up to two missed cleavages; carbamidomethylation $(+57.02146 \mathrm{Da})$ on cysteine, TMT reagent adducts $(+229.162932 \mathrm{Da})$ on lysine and peptide amino termini were set as a fixed modification; and methionine oxidation $(+15.99492 \mathrm{Da})$ was set as a variable modification. False discovery rates (FDR) of the identified peptides and proteins were estimated by searching against the database with the reversed amino acid sequence. Only peptides with at least six amino acids in length and an FDR of 1\% were considered to be successfully identified. Relative protein abundance ratios between two groups were calculated from TMT reagent reporter ion intensities from HCD spectra. For TMT labeling, each peptide channel was re-normalized by the sum across channels. The protein intensity was calculated as the median of normalized intensity of the corresponding peptides. The mean and standard deviation for each protein across subjects was calculated, and Perseus was used to perform statistical comparisons. One-way analysis of variance (ANOVA) was used to calculate significant differences in abundance among groups. A permutation-based FDR value less than 0.05 was considered significant.

\section{Ingenuity pathway analysis}

To further explore the significance of the differentially expressed plasma membrane proteins, Ingenuity ${ }^{\bullet}$ Pathway Analysis (IPA; Ingenuity ${ }^{\circ}$ Systems, www.ingenuity.com/) was used to search the relevant molecular functions, cellular processes and pathways of these identified proteins during the pathological changes of GC. Associated networks of differentially expressed plasma membrane proteins were generated, along with a score representing the log probability of a particular network being found by random chance. Top canonical pathways associated with the uploaded data were presented, along with a p-value. The p-values were calculated using right-tailed Fisher's exact tests.

\section{Western blot analyses}

Lysates from normal or GC plasma membrane samples were separated on $11.5 \%$ SDS-PAGE gels and then the proteins were transferred to nitrocellulose membranes, blocked in TBST containing 5\% nonfat milk powder for 4 hour and incubated overnight with primary antibodies against $\mathrm{Na}^{+} / \mathrm{K}^{+}$-ATPase(Abcam Ab76020, 1:1000), prohibitin(Abcam Ab28172, 1:1000), Golgi 58(Abcam Ab27043, 1:500), histone H2A(Abcam Ab18255, 1:1000), sigma non-opioid intracellular receptor 1(Abcam Ab160924, Cambridge, UK; 1:1000), flotillin 1(Abcam Ab41927, 1:500), CD36 (Abcam Ab78054, 1:500) and CD9 molecule (Abcam Ab65230, 1:500), then washed three times with TBST. The membranes were incubated for 1 hour with alkaline phosphatase (AP)-conjugated antimouse or rabbit IgG. The protein levels were evaluated by the detection of activity of alkaline phosphatase using a Lumi-Phos kit (Pierce Biotechnology). The visualized bands of western blot were quantified with BioRad QUANTITY ONE software. The volumes of target bands were normalized to GAPDH. The average absolute intensity and the standard deviation were determined. The protein ratio was determined using these averaged values. Student's T-test was used to generate $\mathrm{p}$ values. Significant difference was recognized as a $\mathrm{p}$ value less than 0.05 .

\section{Immunohistochemistry and tissue microarray}

For expression studies of human flotillin 1 in clinical samples, we used tissue microarrays purchased from Biomax, Inc. [ST1004 and bST801a)] containing cores from a total of 85 different cases of GC with matched adjacent normal tissues and an additional 10 normal only tissues. IHC of tissue arrays was done as described previously. Flotillin 1 protein expression was assessed using a previously described semiquantitative scoring 
consisting of an assessment of both staining intensity (scale 0 to 3 ) and the percentage of positive cells (0 to $100 \%)$, which, when multiplied, generate a score ranging from 0 to 300. Statistical analysis was done using SPSS 18.0. The $t$ test was performed at $95 \%$ confidence.

\section{Results}

Detection of plasma membrane proteins in GC and adjacent normal tissues

The experimental workflow of this study is shown in Figure 1. To discover plasma membrane protein alterations associated with $\mathrm{GC}$, six pools of plasma membrane samples (three controls and three GC) were generated by pooling samples from 4 subjects for each pool. The purity of the plasma membrane after Percoll density gradient centrifugation was detected by western blot analysis. Figure 2 indicated that the plasma membrane was highly enriched in the marker, $\mathrm{Na}^{+} / \mathrm{K}^{+}$-ATPase, compared to the total lysis fraction. A total of 501 proteins were identified in the workflow (Additional file 1: Table S1). To further assess the efficacy of the protocol for the enrichment of plasma membrane proteins, the subcellular locations and functions were cataloged according to the gene ontology (GO) component annotations from literatures. Figure 3 showed that 175 proteins (about 35\%) have been assigned as plasma membrane or membrane-associated proteins. Of the remaining proteins with subcellular annotation, approximately $16.9 \%$ of the identified proteins are extracellular, and $20.1 \%$ proteins locate in cytoplasm. $10 \%$ proteins locate in mitochondria and $11.5 \%$ proteins are nuclear or nuclear associated proteins. Other $6.5 \%$ proteins are mainly from cytoskeleton and endoplasmic reticulum.

\section{Quantification of plasma membrane proteins in GC and adjacent normal tissues}

Proteins were labeled with TMT reagents and analyzed using tandem mass spectrometry to screen for the differentially expressed proteins between GC and adjacent normal tissues. To increase the coverage of protein identifications and the confidence of the data generated,

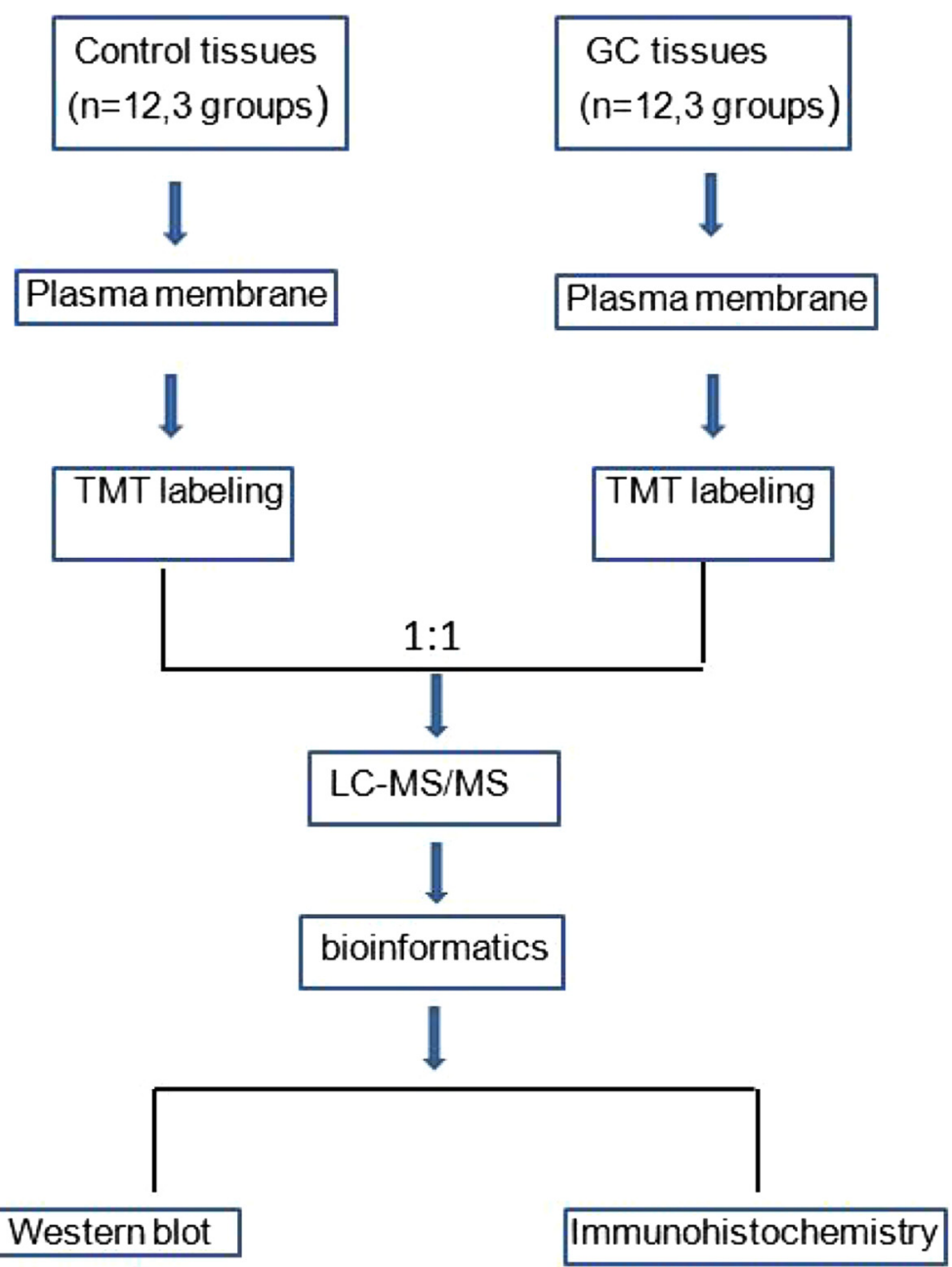

Figure 1 Schematic representation of the strategy used to identify the differentially expressed proteins in GC tissues. 


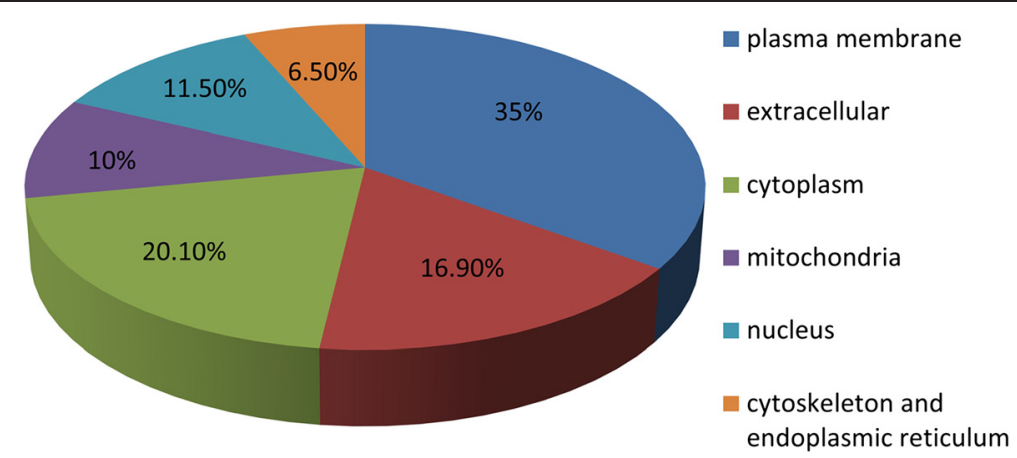

Figure 2 Western blot analysis of the plasma membrane from GC and control tissues after Percoll density gradient centrifugation; The same amount of proteins $(50 \mu \mathrm{g})$ was loaded on each lane.

three pools of adjacent normal tissues were labeled with TMT reagents 126, 127 and 128 respectively; pools of GC tissues were labeled with TMT reagents 129, 130 and 131 respectively. The relative quantification analysis by Maxquant 1.2.2.5 software comes with statistical analysis, however, most methods are prone to technical variation, so we included an additional 1.5-fold cut off for all TMT ratios to add stringency when classifying proteins as up- or down-regulated. A total of 205 differentially expressed proteins proteins were identified with 95\% confidence (Additional file 2: Table S2). Of these, 82 plasma membrane proteins were found to have $>1.5$ fold difference in expression between the GC and adjacent normal tissues (Table 1). 24 proteins were downregulated in gastric cancer, whereas 58 were overexpressed compared to adjacent normal tissues. The plasma membrane/ plasma membrane -associated proteins comprised about $40 \%$ of the total proteins detected. The mass spectra of four representative proteins (sigma non-opioid intracellular receptor 1, flotillin 1, CD36 and CD9 molecule) were shown in Figure 4.
Functional characteristics of the proteins detected in GC and adjacent normal tissues

To better appreciate the molecular and functional characteristics of the 82 differentially expressed plasma membrane or membrane-associated proteins, these proteins were subjected to IPA analysis for further identification of important biological processes that they were significantly involved in. The over-represented biological processes, molecular functions, and canonical pathways were generated based on information contained in the Ingenuity Pathways Knowledge Base. We found that the top three significant biological processes of the differentially expressed proteins in our study were networks describing 1) cancer, renal and urological system development and function, tissue morphology; 2) cell-to-cell signaling and interaction, infectious disease, cellular function and maintenance; 3) cellular assembly and organization, nervous system development and function, cellular movement. For molecular and cellular functions, the data indicated that many proteins involved in cellular function and maintenance, cell-to-cell signaling and

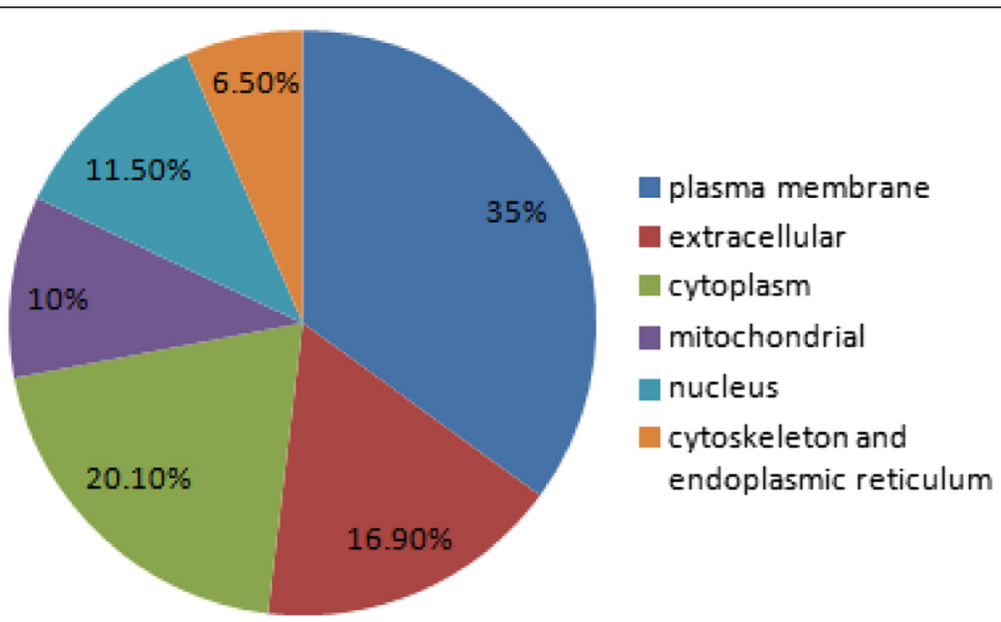

Figure 3 The subcellular locations of the identified proteins from GC and normal tissues according to the GO annotations and literature. 
Table 1 Differentially regulated plasma membrane proteins identified in GC tissues

\begin{tabular}{|c|c|c|c|c|c|}
\hline Accession No. & Gene symbols & Description & TMT ratio & $P$ value & Function \\
\hline Q12959 & DLG1 & discs, large homolog 1 (Drosophila) & -8.78 & $1.28 \mathrm{E}-05$ & kinase \\
\hline G8JLH6 & CD9 & CD9 molecule & -3.723 & $7.04 \mathrm{E}-02$ & other \\
\hline P30453 & HLA-A & major histocompatibility complex, class I, A & -2.903 & 7.40E-04 & other \\
\hline O95810 & SDPR & serum deprivation response & -2.623 & 1.69E-09 & other \\
\hline P48960 & CD97 & CD97 molecule & -2.615 & $3.74 \mathrm{E}-01$ & G-protein coupled receptor \\
\hline Q16853 & $\mathrm{AOC} 3$ & amine oxidase, copper containing 3 & -2.314 & 1.11E-10 & enzyme \\
\hline E7EWP3 & MPZ & myelin protein zero & -2.266 & $2.45 \mathrm{E}-07$ & other \\
\hline Q03135 & CAV1 & caveolin 1, caveolae protein, $22 \mathrm{kDa}$ & -2.251 & $2.43 \mathrm{E}-10$ & transmembrane receptor \\
\hline P41219 & $\mathrm{PRPH}$ & peripherin & -2.149 & 1.65E-08 & other \\
\hline P43121 & MCAM & melanoma cell adhesion molecule & -2.115 & 1.93E-09 & other \\
\hline Q9HAVO & GNB4 & guanine nucleotide binding protein (G protein), beta polypeptide 4 & -1.976 & 9.69E-04 & enzyme \\
\hline Q86UP2 & KTN1 & kinectin 1 (kinesin receptor) & -1.959 & 7.69E-03 & transmembrane receptor \\
\hline P01859 & IGHG2 & immunoglobulin heavy constant gamma 2 (G2m marker) & -1.844 & 1.43E-02 & other \\
\hline B7Z2R4 & SGCE & sarcoglycan, epsilon & -1.791 & 2.91E-02 & other \\
\hline P18206 & $\mathrm{VCL}$ & vinculin & -1.685 & $2.01 \mathrm{E}-10$ & enzyme \\
\hline AOFGR8 & ESYT2 & extended synaptotagmin-like protein 2 & -1.672 & $2.68 \mathrm{E}-03$ & other \\
\hline P08133 & ANXA6 & annexin A6 & -1.668 & 1.10E-11 & ion channel \\
\hline O43491 & EPB41L2 & erythrocyte membrane protein band 4.1 -like 2 & -1.66 & $1.05 \mathrm{E}-08$ & other \\
\hline Q14BN4 & SLMAP & sarcolemma associated protein & -1.645 & $6.33 \mathrm{E}-04$ & other \\
\hline A6NMH8 & CD81 & CD81 molecule & -1.634 & 3.17E-04 & other \\
\hline Q96CX2 & KCTD12 & potassium channel tetramerization domain containing 12 & -1.559 & 3.59E-08 & ion channel \\
\hline Q9H223 & EHD4 & EH-domain containing 4 & -1.527 & 1.30E-03 & enzyme \\
\hline Q13418 & ILK & integrin-linked kinase & -1.526 & $1.20 \mathrm{E}-09$ & kinase \\
\hline P16671 & CD36 & CD36 molecule (thrombospondin receptor) & -1.501 & 1.16E-06 & transmembrane receptor \\
\hline P38606 & ATP6V1A & ATPase, $\mathrm{H}+$ transporting, lysosomal $70 \mathrm{kDa}$, $\mathrm{V} 1$ subunit $\mathrm{A}$ & 1.514 & $3.79 \mathrm{E}-05$ & transporter \\
\hline Q14108 & SCARB2 & scavenger receptor class $B$, member 2 & 1.514 & $1.92 \mathrm{E}-08$ & other \\
\hline P01903 & HLA-DRA & major histocompatibility complex, class II, DR alpha & 1.521 & 2.94E-08 & transmembrane receptor \\
\hline Q14444 & CAPRIN1 & cell cycle associated protein 1 & 1.529 & 1.30E-06 & other \\
\hline Q6IAA8 & LAMTOR1 & late endosomal/lysosomal adaptor, MAPK and MTOR activator 1 & 1.533 & $5.18 \mathrm{E}-03$ & other \\
\hline P27216 & ANXA13 & annexin A13 & 1.536 & 3.38E-09 & other \\
\hline Q9Y287 & ITM2B & integral membrane protein $2 \mathrm{~B}$ & 1.553 & 7.16E-02 & other \\
\hline Q9Y6R1 & SLC4A4 & $\begin{array}{l}\text { solute carrier family } 4 \text { (sodium bicarbonate cotransporter), } \\
\text { member } 4\end{array}$ & 1.558 & $2.21 \mathrm{E}-04$ & transporter \\
\hline
\end{tabular}


Table 1 Differentially regulated plasma membrane proteins identified in GC tissues (Continued)

\begin{tabular}{|c|c|c|c|c|c|}
\hline Q8WW4 & POF1B & premature ovarian failure, 1B & 1.568 & 9.94E-09 & other \\
\hline D6RH31 & NPNT & nephronectin & 1.59 & $1.40 \mathrm{E}-05$ & other \\
\hline Q9P0L0 & VAPA & $\begin{array}{l}\text { VAMP (vesicle-associated membrane protein)-associated } \\
\text { protein } \mathrm{A}, 33 \mathrm{kDa}\end{array}$ & 1.597 & 7.50E-06 & other \\
\hline P02786 & TFRC & transferrin receptor & 1.602 & 3.53E-01 & transporter \\
\hline 000203 & AP3B1 & adaptor-related protein complex 3 , beta 1 subunit & 1.619 & $5.16 \mathrm{E}-03$ & transporter \\
\hline Q00610 & CLTC & clathrin, heavy chain $(\mathrm{Hc})$ & 1.623 & $6.18 \mathrm{E}-11$ & other \\
\hline P26006 & ITGA3 & $\begin{array}{l}\text { integrin, alpha } 3 \text { (antigen CD49C, alpha } 3 \text { subunit of VLA-3 } \\
\text { receptor) }\end{array}$ & 1.645 & $3.24 \mathrm{E}-08$ & other \\
\hline 095292 & VAPB & VAMP (vesicle-associated membrane protein)-associated protein B and C & 1.652 & 4.17E-05 & other \\
\hline B4DNJ6 & STRAP & serine/threonine kinase receptor associated protein & 1.654 & 4.56E-03 & other \\
\hline B5MCA4 & EPCAM & epithelial cell adhesion molecule & 1.655 & 4.47E-03 & other \\
\hline Q14247 & CTTN & cortactin & 1.664 & $2.58 \mathrm{E}-06$ & other \\
\hline C9JME2 & FARP1 & $\begin{array}{l}\text { FERM, RhoGEF (ARHGEF) and pleckstrin domain protein } 1 \\
\text { (chondrocyte-derived) }\end{array}$ & 1.667 & 4.07E-10 & other \\
\hline P15144 & ANPEP & alanyl (membrane) aminopeptidase & 1.693 & $7.85 \mathrm{E}-10$ & peptidase \\
\hline G5EA09 & SDCBP & syndecan binding protein (syntenin) & 1.71 & $1.01 \mathrm{E}-06$ & enzyme \\
\hline O75955 & FLOT1 & flotillin 1 & 1.727 & 2.09E-02 & other \\
\hline Q86XK7 & VSIG1 & V-set and immunoglobulin domain containing 1 & 1.727 & 1.27E-04 & other \\
\hline P00533 & EGFR & epidermal growth factor receptor & 1.755 & 2.27E-01 & kinase \\
\hline P17301 & ITGA2 & integrin, alpha 2 (CD49B, alpha 2 subunit of VLA-2 receptor) & 1.786 & 1.19E-08 & transmembrane receptor \\
\hline P29992 & GNA11 & guanine nucleotide binding protein (G protein), alpha 11 (Gq class) & 1.786 & $7.56 \mathrm{E}-02$ & enzyme \\
\hline C9J6P4 & ZC3HAV1 & zinc finger $\mathrm{CCCH}$-type, antiviral 1 & 1.835 & $3.35 \mathrm{E}-09$ & other \\
\hline P27105 & STOM & stomatin & 1.844 & $1.31 \mathrm{E}-04$ & other \\
\hline P46977 & STT3A & STT3A, subunit of the oligosaccharyltransferase complex (catalytic) & 1.895 & 5.89E-05 & enzyme \\
\hline Q9BX66 & SORBS1 & sorbin and $\mathrm{SH} 3$ domain containing 1 & 1.895 & $1.62 \mathrm{E}-08$ & other \\
\hline O95563 & MPC2 & mitochondrial pyruvate carrier 2 & 1.917 & $2.32 \mathrm{E}-08$ & other \\
\hline P09496 & CLTA & clathrin, light chain A & 1.926 & $1.13 \mathrm{E}-12$ & other \\
\hline Q13155 & AIMP2 & aminoacyl tRNA synthetase complex-interacting multifunctional protein 2 & 1.928 & $1.03 \mathrm{E}-07$ & other \\
\hline P09497 & CLTB & clathrin, light chain B & 1.954 & 1.00E-10 & other \\
\hline $\mathrm{H} 9 \mathrm{KV} 28$ & DIAPH1 & diaphanous-related formin 1 & 1.958 & $8.62 \mathrm{E}-04$ & other \\
\hline Q99720 & SIGMAR1 & sigma non-opioid intracellular receptor 1 & 1.961 & $3.62 \mathrm{E}-04$ & G-protein coupled receptor \\
\hline P13473 & LAMP2 & lysosomal-associated membrane protein 2 & 1.999 & $5.05 \mathrm{E}-10$ & enzyme \\
\hline $\mathrm{F} 5 \mathrm{H} 7 \mathrm{~K} 4$ & NCEH1 & neutral cholesterol ester hydrolase 1 & 2.006 & $5.68 \mathrm{E}-04$ & enzyme \\
\hline
\end{tabular}


Table 1 Differentially regulated plasma membrane proteins identified in GC tissues (Continued)

\begin{tabular}{|c|c|c|c|c|c|}
\hline P11215 & ITGAM & integrin, alpha M (complement component 3 receptor 3 subunit) & 2.012 & $2.29 \mathrm{E}-10$ & transmembrane receptor \\
\hline P15924 & DSP & desmoplakin & 2.031 & $8.86 \mathrm{E}-13$ & other \\
\hline Q9UGM3 & DMBT1 & deleted in malignant brain tumors 1 & 2.079 & $2.59 \mathrm{E}-06$ & transmembrane receptor \\
\hline Q93008 & USP9X & ubiquitin specific peptidase 9, X-linked & 2.19 & $1.22 \mathrm{E}-01$ & peptidase \\
\hline 015400 & STX7 & syntaxin 7 & 2.208 & $1.94 \mathrm{E}-07$ & transporter \\
\hline Q9BXJ0 & C1QTNF5 & $\mathrm{Clq}$ and tumor necrosis factor related protein 5 & 2.223 & 2.33E-04 & transmembrane receptor \\
\hline Q9UJZ1 & STOML2 & stomatin (EPB72)-like 2 & 2.228 & 1.06E-04 & other \\
\hline P55011 & SLC12A2 & $\begin{array}{l}\text { solute carrier family } 12 \text { (sodium/potassium/chloride } \\
\text { transporter), member } 2\end{array}$ & 2.332 & $5.91 \mathrm{E}-11$ & transporter \\
\hline 000182 & LGALS9 & lectin, galactoside-binding, soluble, 9 & 2.45 & 1.39E-05 & other \\
\hline Q08380 & LGALS3BP & lectin, galactoside-binding, soluble, 3 binding protein & 2.469 & 4.66E-06 & transmembrane receptor \\
\hline Q9UGl8 & TES & testis derived transcript (3 LIM domains) & 2.577 & 1.55E-06 & other \\
\hline Q9NZ01 & TECR & trans-2,3-enoyl-CoA reductase & 2.83 & 1.45E-07 & enzyme \\
\hline G3V1K3 & PON2 & paraoxonase 2 & 2.932 & 3.93E-06 & enzyme \\
\hline O95841 & ANGPTL1 & angiopoietin-like 1 & 3.109 & 4.33E-04 & other \\
\hline Q92542 & NCSTN & nicastrin & 3.634 & $3.58 \mathrm{E}-02$ & peptidase \\
\hline O95497 & VNN1 & vanin 1 & 3.718 & $1.00 \mathrm{E}-08$ & enzyme \\
\hline P16144 & ITGB4 & integrin, beta 4 & 3.792 & $2.40 \mathrm{E}-01$ & transmembrane receptor \\
\hline Q96HR9 & REEP6 & receptor accessory protein 6 & 3.797 & $2.70 \mathrm{E}-08$ & other \\
\hline P48230 & TM4SF4 & transmembrane $4 \mathrm{~L}$ six family member 4 & 4.71 & 1.42E-04 & other \\
\hline
\end{tabular}


A

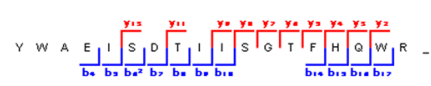

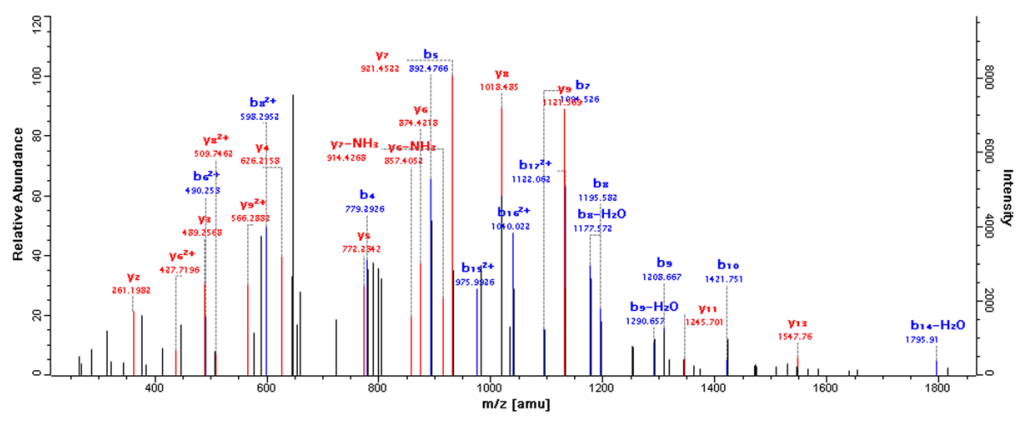

B

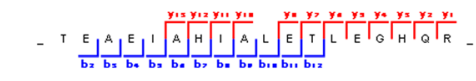

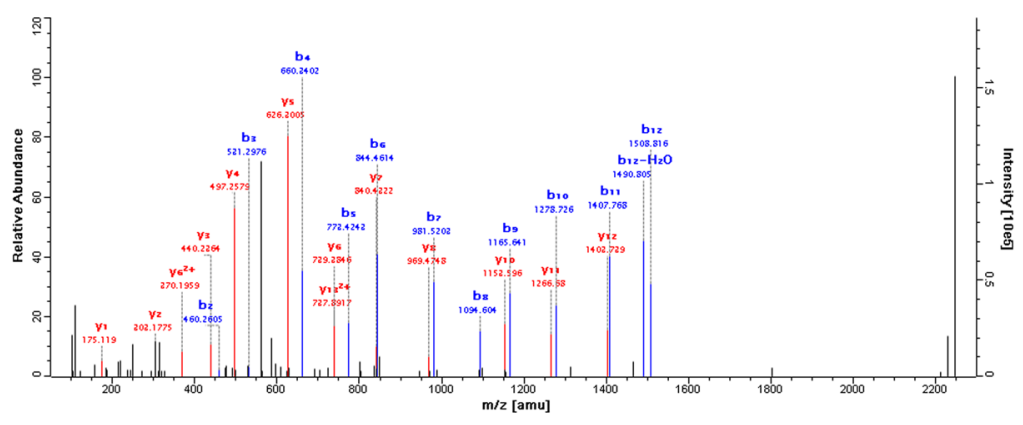

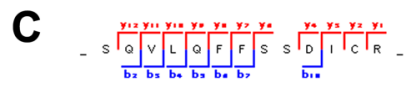

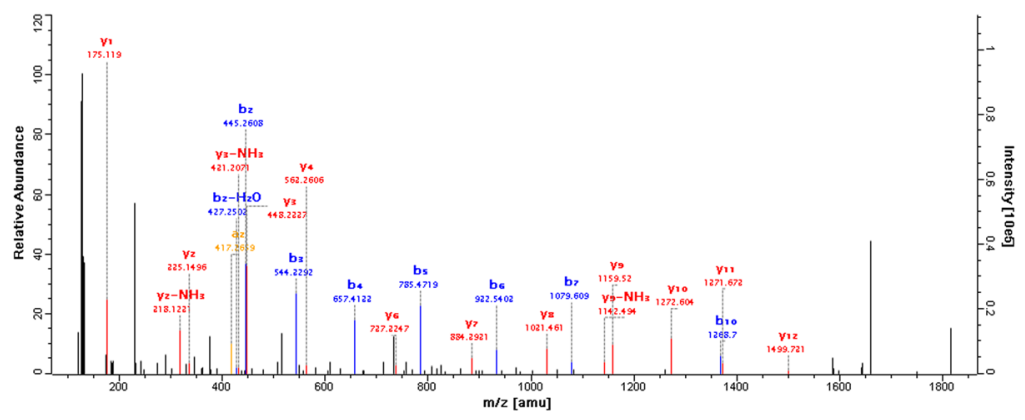

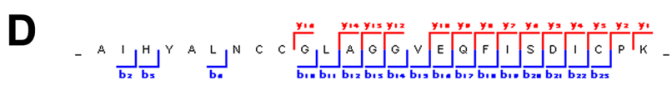

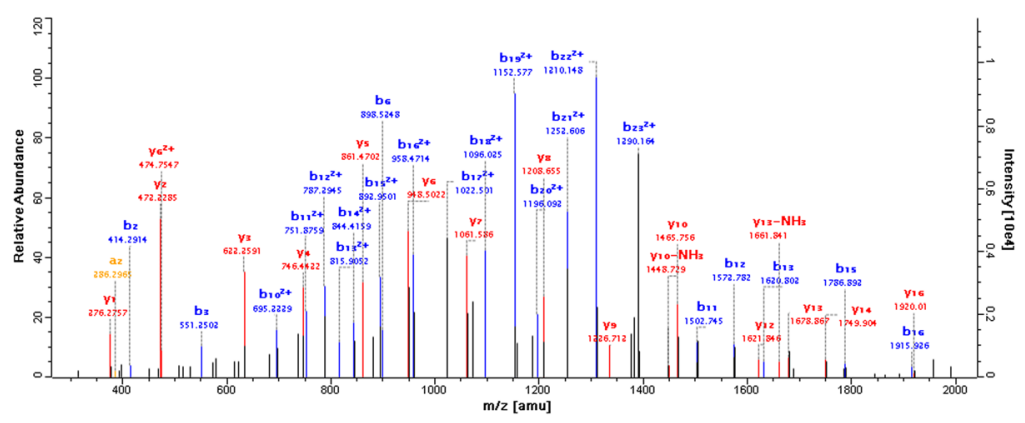

Figure 4 Mass spectra of four representative proteins. (A) sigma non-opioid intracellular receptor 1, (B) flotillin 1, (C) CD 36 and (D) CD9. 
interaction, cell morphology and cellular movement. Our results showed that the top three canonical pathways of differentially expressed proteins participated in were virus entry via endocytic pathways, caveolarmediated endocytosis signaling and integrin signaling (Figure 5).

\section{Confirmation of differentially expressed proteins by western blotting}

Western blot analyses were performed on selected candidates (sigma non-opioid intracellular receptor 1, flotillin 1, CD 36 and CD9 molecule). These candidates were chosen based on the plasma membrane markers not known previously reported to be differentially expressed in gastric cancer since the key objective of this study is to identify potential biomarkers of GC. Figure 6 shows that the up- or down-regulation trend of candidate proteins between GC and normal tissue revealed by the Western blot data is congruent with that revealed by quantitative proteomic method. A positive correlation for the direction of changes was observed. The result of western blotting provides evidence that the TMT labeling method for the large scale protein quantification was reliable.

\section{Flotillin 1 is relevant to clinical gastric cancer as a potential target}

To assess the clinical relevance, we examined the expression of flotillin 1 in tissue microarrays containing 85 matched normal and gastric cancer tissues by immunohistochemistry (Additional file 3: Table S3). The TMA also includes ten additional unmatched normal gastric tissues. The expression levels of flotillin 1 across the clinical samples are presented in a distribution plot (Figure 7). Two-samples t test revealed that the expression of flotillin 1 in cancer/tumor samples is significantly higher than that of noncancer/normal tissues $(\mathrm{p}<0.01)$. In addition, $50.5 \%(43 / 85)$ of the matched cases showed higher flotillin 1 expression in the tumor compared to normal tissues while only $13 \%$ of the matched cases showed the reverse trend (Figure 7). 36.5\% of the matched cases had no detectable level of flotillin 1 . The expression data from clinical samples analysis revealed that the upregulation of flotillin 1 has quite a high penetrance $(>40 \%)$ in gastric cancer. Representative images of the immunohistochemistry of flotillin 1 in 2 sets of matched normal and gastric cancer tissues are shown in Figure 7.

\section{Discussion}

Although the prevalence of gastric cancer is declining and varying geographically, it remains one of the most common cancers in worldwide [1,2,23]. Five-year survival rates have ranged from $90 \%$ to less than $5 \%$, mainly depending on the stage of diagnosis [24]. If gastric cancer can be detected and treated in early stages(stage I), the five-year survival rate is better than $90 \%$. Unfortunately, no reliable diagnostic biomarkers exist for early detection of gastric cancer [25]. In order to dig out new drug targets or biomarkers, methods such as subcellular proteome research were adopted to offer new insights [26]. Because most of the drug targets are proteins located in the plasma membrane, we specifically focused our study on the plasma membrane proteome [27]. In this research, we used a percoll/sucrose density gradient approach for plasma membrane enrichment combined with TMT technology using nano liquid chromatography-tandem mass spectrometry analysis to identify specifically differentially expressed proteins in GC tissues compared with adjacent normal tissues. Based on the stringent criteria, in the present study, 82 plasma membrane proteins were identified as differentially expressed

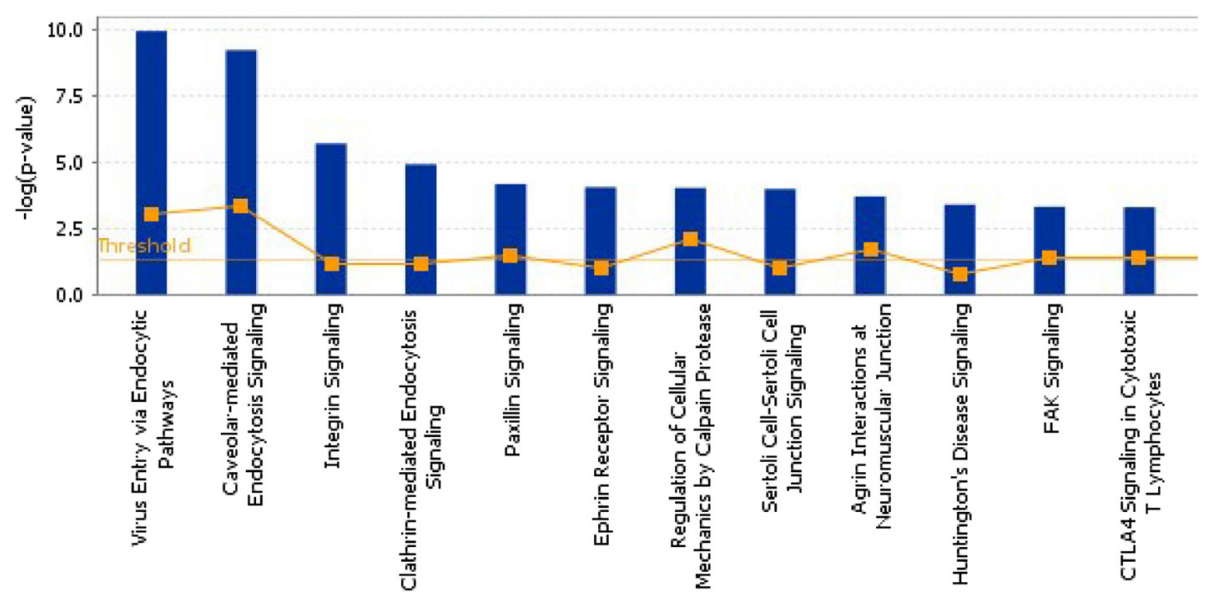

Figure 5 Ingenuity Pathway Analysis of proteins that were significantly altered in pathways. 


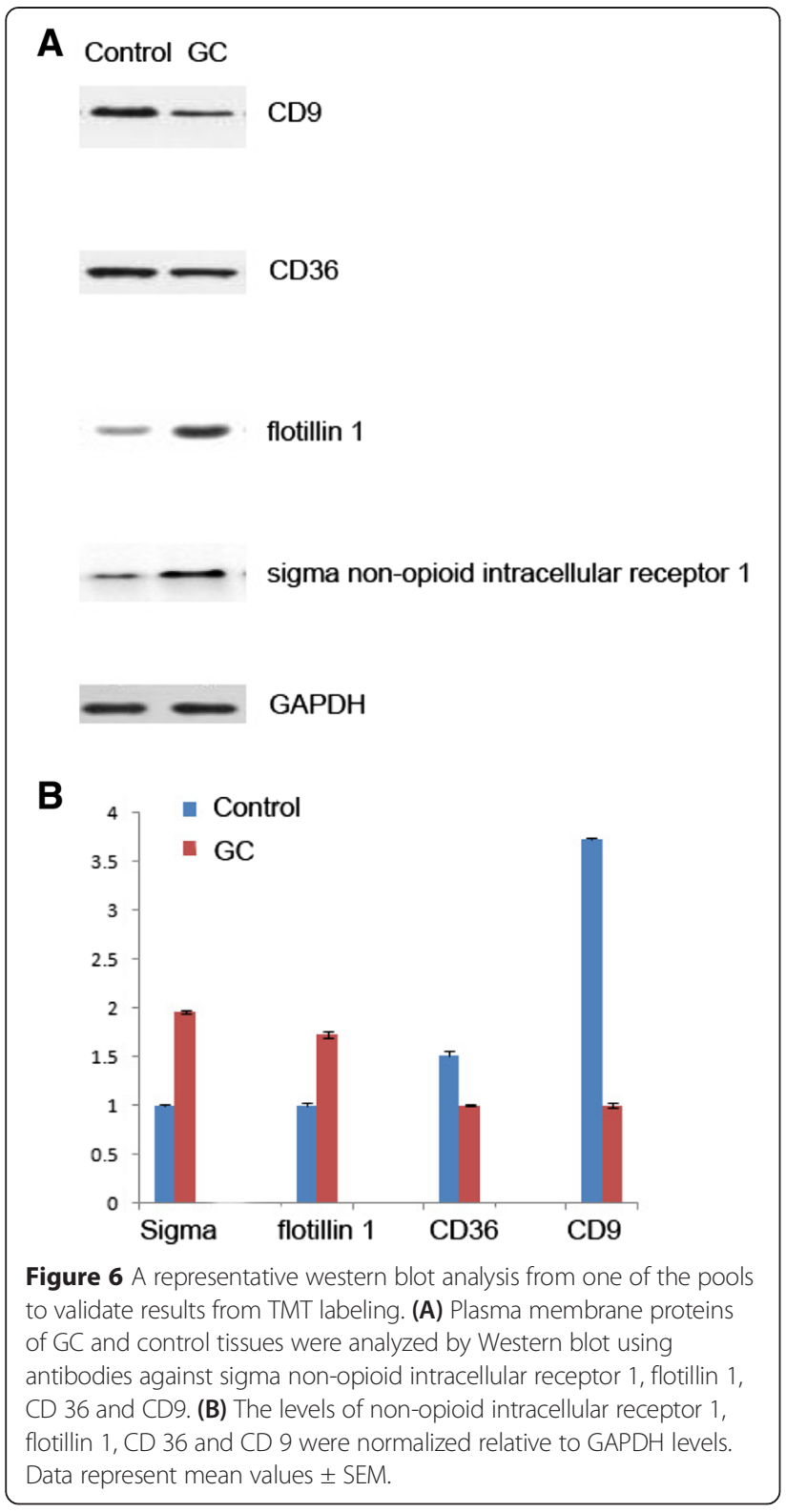

proteins in GC, of which 58 proteins were increased and 24 were decreased. Discs, large homolog 1 protein is the most decreased protein and transmembrane $4 \mathrm{~L}$ protein is the most increased protein in GC tissue. Some lowabundance plasma membrane proteins such as potassium channel tetramerization domain containing 12 , sigma nonopioid intracellular receptor 1 were found.

Previously studies have found a number of markers (e.g. annexin A6, caveolin 1, epidermal growth factor receptor, integrin beta 4) measured in the first and early second trimesters which are associated with the diagnosis of GC [28-35]. Annexin A6 functions as a tumor suppressor in gastric cancer cells through the inhibition of Ras/MAPK signaling [36]. Caveolin-1 promotes gastric cancer progression by up-regulating epithelial to mesenchymal transition by crosstalk of signalling mechanisms under hypoxic condition. Human epidermal growth factor receptor (EGFR) which belongs to EGFR family is overexpressed in a significant proportion of cases of GC to promote metastasis of cancer [37]. Integrin beta 4 expressions are positively correlated in gastric cancer cell lines and tissues [33]. The survival analyses show that the expression of integrin beta 4 is associated with poor outcomes in gastric cancer patients [38]. Our prospective studies have confirmed these validated biomarkers. In addition, many potentially novel biomarkers of GC were found, such as CD36,CD81,CD9,CD97 and so on. As demonstrated here, TMT labeling combined with LC-MS/MS is a powerful tool for the identification of membrane protein biomarkers of GC.

It is reported that endocytosis is enhanced and skewed in cancer cells [39]. Endocytosis is multicomponent process which entails selective packaging of cell-surface proteins, such as receptors for cytokines and adhesion components, in cytoplasmic vesicles (endosomes). The series of sorting events that determines the fate of internalized proteins, either degradation in lysosomes or recycling back to the plasma membrane. Many proteins involved in endocytosis have been reported to be perturbed in human cancers [40]. In this research, proteins such as caveolin 1, epidermal growth factor receptor, major histocompatibility complex, integrin, cortactin, transferrin receptor, ubiquitin specific peptidase 9 participated in caveolae /clathrin mediated endocytosis were found as differentially expressed proteins. Caveolae, subsarcolemmal membrane compartments, have been implicated in signal transduction and vesicular trafficking [41]. Caveolae are capable of removing proteins from the plasma membrane by sequestration and endocytotic mechanism [42]. Clathrin-mediated endocytosis is the endocytic portal into cells through which cargo is packaged into vesicles with the aid of a clathrin coat [43]. Clathrin heavy chain and cortactin have been reported to have their expression levels changed in breast cancer $[44,45]$. These two proteins were also found overexpressed in GC tissues in this research. However, proteins such as flotillin 1 involved in clathrin-mediated endocytosis have not been reported to differentially expressed in GC tumours in previous researches. The flotillin protein family has been demonstrated to be involved in the development and progression of various cancers. Flotillin 1 is highly conserved protein that localize into specific cholesterol rich microdomains in cellular membranes [46]. Flotillin-2 is a major protein from caveolae/lipid raft and is involved in epidermal cell adhesion. Recent findings have revealed that flotillin 1 and flotillin 2 are frequently overexpressed in various types of human cancers including lung adenocarcinoma, nasopharyngeal carcinoma [47], 


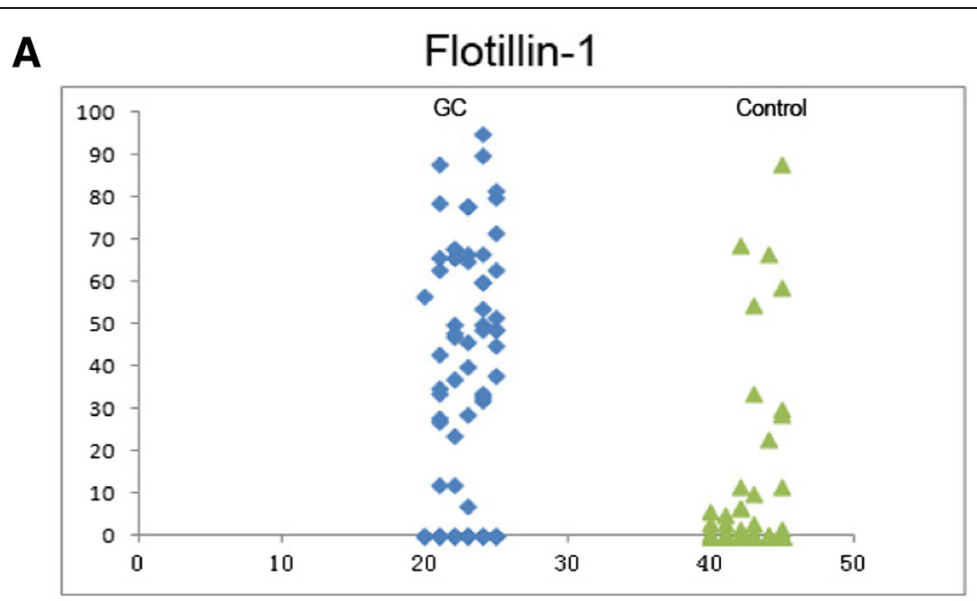

B
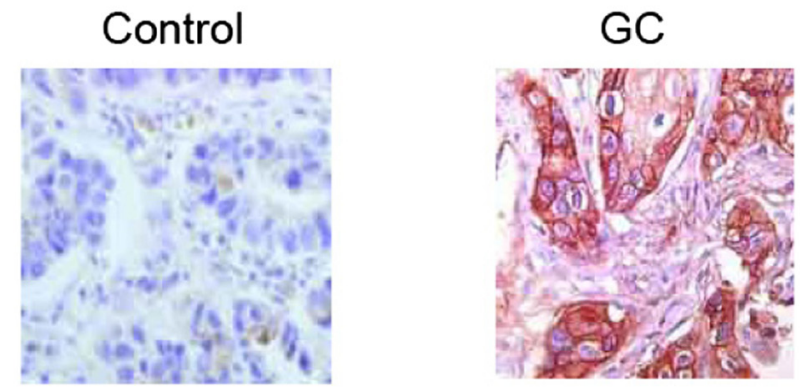

\begin{tabular}{|l|l|l|l|}
\hline Trend & GC $>$ Control & GC $=$ Control & GC $<$ Control \\
\hline Frequency & $50.5 \%(43 / 85)$ & $36.5 \%(31 / 85)$ & $13 \%(11 / 85)$ \\
\hline
\end{tabular}

Figure 7 Immunohistochemistry of flotillin 1 in tissue microarrays of clinical gastric samples. A total of 85 matched normal and cancer tissues plus addition 10 normal tissues were analyzed. (A) Distribution plot of the IHC scores of flotillin 1 in individual normal and gastric cancer samples. (B) Representative IHC images (10x magnification) of flotillin 1 in 2 matched gastric cancer and normal tissues.

esophageal squamous cell carcinoma, breast cancer and hepatocellular carcinoma [48]. Importantly, recent researches have suggested that the flotillin 2 protein expression is significantly correlated with cancer progression and poor prognosis in gastric carcinomas, probably due to its role in the regulation of cell proliferation, migration, and invasion in gastric carcinoma cells [49,50]. However, flotillin 2 was not identified in our research. After analysis of spotted sequences, we found the peptide similarities of flotillin 1 and 2 were low, as described in supplemental Figure 1 (Additional file 4: Figure S1). In this research, abnormal expression of flotillin 1 has been also confirmed in clinical gastric cancers in this study. For the first time, the association of flotillin 1 in gastric cancer has been established in our study, suggesting that flotillin 1 is a promising candidate for future biomarker development for gastric cancer.

\section{Conclusion}

With the help of proteomics analysis, we discovered that a series of plasma membrane proteins showed an altered expression level in GC tissues. 82 plasma membrane proteins with functional relevance to $\mathrm{GC}$ were found to be significantly different between GC and control tissues. Our approach allowed us to identify a number of markers (e.g. annexin A6, caveolin 1 ,epidermal growth factor receptor, integrin beta 4) that were previously reported as biomarkers of GC. Additionally, we have presented several potential biomarkers participated in endocytosis pathway and integrin signaling pathway were firstly identified differentially expressed in GC samples. Our findings also suggest that flotillin 1 may be a novel biomarker for GC.These findings will not only benefit early diagnosis of this cancer at the molecular level but also improve our understanding of the initiation and development of GC.

\section{Additional files}

Additional file 1: Table S1. All of identified proteins in this research. 
Additional file 2: Table S2. The list of the differentially expressed proteins in GC samples.

Additional file 3: Table S3. Raw $I H C$ scores of climnical samples used in TMAS.

Additional file 4: Figure S1. CLUSTAL 2. 1 multiple sequence alignment.

\section{Competing interests}

The authors declare that they have no competing interests.

\section{Authors' contributions}

WG, JX, FW and JW are responsible for the hypothesis development and overall design of the research and experiment, and supervised the experimental analyses. WG and JW co-wrote the manuscript. WG, JX, FW, LZ, RP, YS, YZ and QT performed all experiments. All authors read and approved the final manuscript.

\section{Acknowledgments}

This study was supported by the Natural Science Foundation of Jiangsu Province (BK2010578,BK20131023) and the National Natural Science Foundation of China (grant no. 81101759,81300363).

\section{Author details}

${ }^{1}$ Key Laboratory of Living Donor Liver Transplantation, Ministry of Public Health, Department of Liver Transplantation Center, The First Affiliated Hospital of Nanjing Medical University, 300 GuangZhou Road, Nanjing 210029, China. ${ }^{2}$ Department of Gastroenterology, The first affiliated hospital of Nanjing medical university, 300 GuangZhou Road, Nanjing 210029, China. ${ }^{3}$ Analysis Center of Nanjing Medical University, 104 Hanzhong Road, 210009 Nanjing, China. ${ }^{4}$ Department of Oncology, The first affiliated hospital of Nanjing medical university, 300 GuangZhou Road, Nanjing 210029, China.

Received: 23 November 2014 Accepted: 22 April 2015

Published online: 07 May 2015

\section{References}

1. Lordick F, Allum W, Carneiro F, Mitry E, Tabernero J, Tan P, et al. Unmet needs and challenges in gastric cancer: the way forward. Cancer Treat Rev. 2014;40(6):692-700.

2. Brenner $\mathrm{H}$, Rothenbacher $\mathrm{D}$, Arndt V. Epidemiology of stomach cancer Methods Mol Biol. 2009;472:467-77.

3. Marrelli D, Roviello F, De Stefano A, Farnetani M, Garosi L, Messano A, et al. Prognostic significance of CEA, CA 19-9 and CA 72-4 preoperative serum levels in gastric carcinoma. Oncology. 1999:57(1):55-62.

4. Offringa R, Huang F. Phosphorylation-dependent trafficking of plasma membrane proteins in animal and plant cells. J Integr Plant Biol. 2013;55(9):789-808

5. Arribas J, Merlos-Suarez A. Shedding of plasma membrane proteins. Curr Top Dev Biol. 2003;54:125-44.

6. Bledi Y, Inberg A, Linial M. PROCEED: A proteomic method for analysing plasma membrane proteins in living mammalian cells. Brief Funct Genomic Proteomic. 2003;2(3):254-65.

7. Rucevic M, Hixson D, Josic D. Mammalian plasma membrane proteins as potential biomarkers and drug targets. Electrophoresis. 2011;32(13):1549-64.

8. Leth-Larsen R, Lund RR, Ditzel HJ. Plasma membrane proteomics and its application in clinical cancer biomarker discovery. Mol Cell Proteomics. 2010;9(7):1369-82.

9. Kohnke PL, Mulligan SP, Christopherson RI. Membrane proteomics for leukemia classification and drug target identification. Curr Opin Mol Ther. 2009;11(6):603-10

10. Carney WP, Bernhardt D, Jasani B. Circulating HER2 extracellular domain: a specific and quantitative biomarker of prognostic value in all breast cancer patients? Biomark Cancer. 2013;5:31-9.

11. Yang ZY, Shen WX, Hu XF, Zheng DY, Wu XY, Huang YF, et al. EGFR gene copy number as a predictive biomarker for the treatment of metastatic colorectal cancer with anti-EGFR monoclonal antibodies: a meta-analysis. J Hematol Oncol. 2012;5:52.

12. Yu S, Yu Y, Zhao N, Cui J, Li W, Liu T. C-Met as a prognostic marker in gastric cancer: a systematic review and meta-analysis. PLoS One. 2013;8(11):e79137.
13. Boja ES, Rodriguez H. Mass spectrometry-based targeted quantitative proteomics: achieving sensitive and reproducible detection of proteins. Proteomics. 2012;12(8):1093-110.

14. Mertins P, Udeshi ND, Clauser KR, Mani DR, Patel J, Ong SE, et al. iTRAQ labeling is superior to MTRAQ for quantitative global proteomics and phosphoproteomics. Mol Cell Proteomics. 2012;11(6):M111 014423.

15. Dayon L, Sanchez JC. Relative protein quantification by MS/MS using the tandem mass tag technology. Methods Mol Biol. 2012;893:115-27.

16. Werner T, Becher I, Sweetman G, Doce C, Savitski MM, Bantscheff M. Highresolution enabled TMT 8-plexing. Anal Chem. 2012;84(16):7188-94.

17. Ruckhaberle E, Karn T, Hanker L, Schwarz J, Schulz-Knappe P, Kuhn K, et al. Breast cancer proteomics - differences in protein expression between estrogen receptor-positive and -negative tumors identified by tandem mass tag technology. Breast Care (Basel). 2010;5(1):7-10.

18. Maes E, Valkenborg D, Mertens I, Broeckx V, Baggerman G, Sagaert X, et al. Proteomic analysis of formalin-fixed paraffin-embedded colorectal cancer tissue using tandem mass tag protein labeling. Mol Biosyst. 2013;9(11):2686-95.

19. Lai X. Reproducible method to enrich membrane proteins with high purity and high yield for an LC-MS/MS approach in quantitative membrane proteomics. Electrophoresis. 2013;34(6):809-17.

20. Wang F, Wang L, Shi Z, Liang G. Comparative N-glycoproteomic and phosphoproteomic profiling of human placental plasma membrane between normal and preeclampsia pregnancies with high-resolution mass spectrometry. PLoS One. 2013;8(11):e80480.

21. Wang F, Wang $L, X u Z$, Liang $G$. Identification and analysis of multi-protein complexes in placenta. PLoS One. 2013;8(4):e62988.

22. Cox J, Neuhauser N, Michalski A, Scheltema RA, Olsen JV, Mann M. Andromeda: a peptide search engine integrated into the MaxQuant environment. J Proteome Res. 2011;10(4):1794-805.

23. Nozaki I, Hato S, Kobatake T, Ohta K, Kubo Y, Nishimura R, et al. Incidence of metachronous gastric cancer in the remnant stomach after synchronous multiple cancer surgery. Gastric Cancer. 2014;17(1):61-6.

24. Howlader N, Ries LA, Mariotto AB, Reichman ME, Ruhl J, Cronin KA. Improved estimates of cancer-specific survival rates from population-based data. J Natl Cancer Inst. 2010;102(20):1584-98.

25. Shimada H, Noie T, Ohashi M, Oba K, Takahashi Y. Clinical significance of serum tumor markers for gastric cancer: a systematic review of literature by the Task Force of the Japanese Gastric Cancer Association. Gastric Cancer. 2014;17(1):26-33.

26. Drissi R, Dubois ML, Boisvert FM. Proteomics methods for subcellular proteome analysis. FEBS J. 2013;280(22):5626-34

27. Herst PM, Berridge MV. Plasma membrane electron transport: a new target for cancer drug development. Curr Mol Med. 2006;6(8):895-904.

28. Wang X, Zhang S, Zhang J, Lam E, Liu X, Sun J, et al. Annexin A6 is downregulated through promoter methylation in gastric cancer. Am J Transl Res. 2013;5(5):555-62

29. Kannan A, Krishnan A, Ali M, Subramaniam S, Halagowder D, Sivasithamparam ND. Caveolin-1 promotes gastric cancer progression by up-regulating epithelial to mesenchymal transition by crosstalk of signalling mechanisms under hypoxic condition. Eur J Cancer. 2014;50(1):204-15.

30. Nam KH, Lee BL, Park JH, Kim J, Han N, Lee HE, et al. Caveolin 1 expression correlates with poor prognosis and focal adhesion kinase expression in gastric cancer. Pathobiology. 2013;80(2):87-94.

31. Liao G, Wang Z, Zhang N, Dong P. Dominant negative epidermal growth factor receptor inhibits growth of human gastric cancer cells by inducing cell cycle arrest and apoptosis. Cancer Biother Radiopharm. 2013;28(6):450-8.

32. Chen C, Yang JM, Hu TT, Xu TJ, Yan G, Hu SL, et al. Prognostic role of human epidermal growth factor receptor in gastric cancer: a systematic review and meta-analysis. Arch Med Res. 2013;44(5):380-9.

33. Yang ZY, Jiang H, Qu Y, Wei M, Yan M, Zhu ZG, et al. Metallopanstimulin-1 regulates invasion and migration of gastric cancer cells partially through integrin beta4. Carcinogenesis. 2013;34(12):2851-60.

34. Caglar GS, Ozdemir ED, Cengiz SD, Demirtas S. Sex-hormone-binding globulin early in pregnancy for the prediction of severe gestational diabetes mellitus and related complications. J Obstet Gynaecol Res. 2012;38(11):1286-93.

35. D'Anna R, Baviera G, De Vivo A, Facciola G, Di Benedetto A, Corrado F. C reactive protein as an early predictor of gestational diabetes mellitus. Reprod Med. 2006:51(1):55-8.

36. Koese M, Rentero C, Kota BP, Hoque M, Cairns R, Wood P, et al. Annexin A6 is a scaffold for PKCalpha to promote EGFR inactivation. Oncogene. 2013;32(23):2858-72 
37. Ema A, Waraya M, Yamashita K, Kokubo K, Kobayashi H, Hoshi K, et al. Identification of EGFR expression status association with metastatic lymph node density (ND) by expression microarray analysis of advanced gastric cancer. Cancer Med. 2015;4(1):90-100.

38. Ishii Y, Ochiai A, Yamada T, Akimoto S, Yanagihara K, Kitajima M, et al. Integrin alpha6beta4 as a suppressor and a predictive marker for peritoneal dissemination in human gastric cancer. Gastroenterology. 2000;1 18(3):497-506.

39. Mellman I, Yarden Y. Endocytosis and cancer. Cold Spring Harb Perspect Biol. 2013;5(12):a016949.

40. Ramanan V, Agrawal NJ, Liu J, Engles S, Toy R, Radhakrishnan R. Systems biology and physical biology of clathrin-mediated endocytosis. Integr Biol (Camb). 2011;3(8):803-15.

41. Sathish V, Thompson MA, Sinha S, Sieck GC, Prakash YS, Pabelick CM. Inflammation, caveolae and CD38-mediated calcium regulation in human airway smooth muscle. Biochim Biophys Acta. 2014;1843(2):346-51.

42. Ariotti N, Fernandez-Rojo MA, Zhou Y, Hill MM, Rodkey TL, Inder KL, et al. Caveolae regulate the nanoscale organization of the plasma membrane to remotely control Ras signaling. J Cell Biol. 2014;204(5):777-92.

43. Godlee C, Kaksonen M. Review series: From uncertain beginnings: initiation mechanisms of clathrin-mediated endocytosis. J Cell Biol. 2013;203(5):717-25.

44. Sheen-Chen SM, Huang CY, Liu YY, Huang CC, Tang RP. Cortactin in breast cancer: analysis with tissue microarray. Anticancer Res. 2011;31(1):293-7.

45. Palaniyandi K, Pockaj BA, Gendler SJ, Chang XB. Human breast cancer stem cells have significantly higher rate of clathrin-independent and caveolinindependent endocytosis than the differentiated breast cancer cells. J Cancer Sci Ther. 2012:4(7):214-22.

46. Meister M, Zuk A, Tikkanen R. Role of dynamin and clathrin in the cellular trafficking of flotillins. FEBS J. 2014;281(13):2956-76.

47. Wen Q, Li J, Wang W, Xie G, Xu L, Luo J, et al. Increased expression of flotillin-2 protein as a novel biomarker for lymph node metastasis in nasopharyngeal carcinoma. PLoS ONE. 2014;9(7):e101676.

48. Zhang Y, Li J, Song Y, Chen F, Pei Y, Yao F. Flotillin-1 expression in human clear-cell renal cell carcinoma is associated with cancer progression and poor patient survival. Mol Med Rep. 2014;10(2):860-6.

49. Cao K, Xie D, Cao P, Zou Q, Lu C, Xiao S, et al. SiRNA-mediated flotillin-2 (Flot2) downregulation inhibits cell proliferation, migration, and invasion in gastric carcinoma cells. Oncol Res. 2014;21(5):271-9.

50. Zhu Z, Wang J, Sun Z, Sun X, Wang Z, Xu H. Flotillin2 expression correlates with HER2 levels and poor prognosis in gastric cancer. PLOS ONE. 2013;8(5):e62365.

\section{Submit your next manuscript to BioMed Central and take full advantage of:}

- Convenient online submission

- Thorough peer review

- No space constraints or color figure charges

- Immediate publication on acceptance

- Inclusion in PubMed, CAS, Scopus and Google Scholar

- Research which is freely available for redistribution 